\title{
DO ESCRITOR EM EXÍLIO CÍVICO à saudável experiência de escrever em liberdade
}

Teresa Cristina Cerdeira da silva

Cavador desta companha Tu dizes que a pena é leve Pesa mais do que a enxada A pena com que se escreve.

Constantino José Diogo (cantador do Alentejo)

O cantador alentejano não leu certamente Camões, que um dia escreveu:

Perdigão, que o pensamento

subiu em alto lugar,

perde a pena do voar

ganha a pena do tormento.

Não tem no ar nem no vento

asas com que se sustenha:

não há mal que lhe não venha.

Quis voar a ua alta torre

mas achou-se desasado;

e, vendo-se depenado,

de puro penado morre,

Se a queixumes se socorre,

lança no fogo mais lenha:

não há mal que lhe não venha. 
Apesar dos ecos e das evidências, insisto que possivelmente o cantador não terá lido Camões, mas nem isso é comprovável nem é bem o que importa, porque aos nossos ouvidos-leitores o Poeta está de qualquer modo convocado pela cantiga popular, quando lemos que a pena que dói, a que voa, e a que escreve se confundem para multiplicar os sentidos e dizer melhor, ou do modo mais rico, que é o de dizer multiplicado. E tem toda razão esse cantador alentejano ao afirmar que "pesa mais do que a enxada / a pena com que se escreve". Escrever é ato incisivo como o da enxada na terra, aquela "faca só lâmina" que João Cabral também já escolhera para metáfora sua. E escrever é ato de dor, ato sensual de terra que se abre. E é ato de dor, ainda, porque a escrita é caminho na contramão. Que se dirá então daquela escrita que, para além da fúria em linguagem, deve lutar contra a fúria do poder instituído contra essa mesma escrita? Tal perplexidade se traduziu, por exemplo, nas palavras do escritor português José Cardoso Pires, em certo dia do ano de 1964, em tempos duros da ditadura salazarista:

Escrevemos sobre um universo cuja face mais significativa é de tal modo sombria e avassaladora que domina todas as outras - a face em que o Pão e a Inteligência são consentidos, não fomentados ${ }^{1}$.

Pão e Inteligência consentidos como esmola, aos bocados, homeopaticamente sancionados, quebra do corpo e da alma para melhor aniquilamento das possíveis revoltas ou das sonhadas utopias. Tempo em que "na gente deu o hábito de caminhar entre as trevas, de murmurar entre as pregas, de tirar leite das pedras, de ver o tempo correr", como cantava o Chico dos nossos também negros anos 70, sem desacreditar, no entanto, que a rosa dos ventos poderia danar-se um dia em que o norte fosse outro. E seria.

O Romantismo instituiu o mito do artista maldito. Mas o poder foi mais longe no lucro que fez deste mito revolucionário. Assimilou-o argutamente, digeriu-o aos bocados e, quando o repetiu, já se esgotara nele a revolução e ficava só a irônica satisfação do artista - exilado da sua história - para ser recuperado, talvez, no futuro da glória possível. Falsa quimera. Engodo ideológico. Banido no presente, o escritor é ausentado (verbo em consciente voz passiva), porque na verdade ele não se ausenta voluntariamente do debate político, conduzido a uma torre de marfim que nem sequer é opção, mas encarceramento. Releio Cardoso Pires: 
Eu bem sei que a Humanidade conta na sua herança cultural uma maioria de génios que sofreram a injustiça e a prepotência dos poderosos e que da adversidade e do protesto tiraram a mensagem do seu talento. Mas nada garante que, numa situação mais feliz, eles não tivessem produzido obras igualmente belas e talvez em maior profusão porque o impulso criador não é forçosamente uma resposta à dor, nasce também da alegria. Nem há nada que disfarce o oportunismo dos instalados quando admiram a rebeldia dos artistas do passado e castigam a dos vivos; ou quando, para admirarem Goya ou Tolstoi, recordam as carnificinas napoleónicas como uma tragédia sem a qual não seriam possíveis algumas obras-primas de dois mestres universais. Em casos destes o elogio vai muito mais para a absolvição dos generais da morte do que para a grandeza da arte. $^{2}$

A reflexão é poderosa porque arrebata do Olimpo o mito artista maldito, para pôr no lugar o homem na História. Porque a sua cantada exclusão, o seu mítico isolamento, serão raramente voluntários, opção consciente de uma alma doente de sociedade. Poderá o artista rebelar-se contra a sociedade, poderá afirmar seu protesto contra os valores que não concebe verdadeiros, manifestará seu descompasso com as leis, mesmo aí não estará ele fora da sociedade. É de dentro dela que reage, é dentro dela que é calado, de dentro dela exilado, nunca verdadeiramente separado. O circuito fechado, o autocentramento, a auto-reflexividade radical da arte geram certamente empobrecimento, raquitismo, estiolação. Todos perdem: o artista, os cidadãos, o país.

Para qualquer artista, vivenciar a censura da sua produção é experiência incontornável. Não porque individualmente ela induza ao banimento e se perca muitas vezes com isso a oportunidade da glória. Muito mais do que a glória pessoal está em jogo nesse dramático pano verde. Mas porque se trata do empobrecimento de gerações, do atraso da consciência cívica, do não exercício das liberdades do cidadão.

Exemplo contundente do sentimento de exílio cívico, que não acontece, aliás, necessariamente através da evidência do expatriamento, é o depoimento de outro escritor português - Alves Redol -, baliza indiscutível do movimento neo-realista. Com aquela sabedoria que parece apurar-se à beira da morte, como lembra Walter Benjamin, escreve ele uma carta-balanço-de-vida ao amigo José Cardoso Pires, em fins de novembro de 1969, em que diz: "Eu sou um dos que morrem na incomunicabilidade com o seu tempo. Nunca me deixaram dizer-lhe o que de mais autêntico tinha para ele", fala do desencanto que se verá comentada poucos dias depois, diante da notícia da sua morte, em outra carta, agora generosamente escrita por Cardoso Pires e endereçada simplesmente "aos amigos comuns". Comuns porque 
em comunidade na amizade e na experiência da incomunicabilidade cívica com o tempo:

$\mathrm{Na}$ morte de qualquer escritor português digno desse nome pesa sempre um remorso do tempo, sempre. É o rastro da mentira e do silêncio, e esse mal, quando não vence uma verdade interior, alastra e cerca-a por outras raízes. Mata primeiro do que o vírus decretado pelas certidões de óbito. [...] Comunicar, na vida de um escritor, é apenas o que se escreve? E o convívio que se lhe nega? E o participar na coletividade com as intervenções que a sua condição lhe solicita? E o viver com alegria e em tranqüilidade? Não é isso também comunicar? Não é escrever, não é? ${ }^{3}$

Se o recorte literário que farei aqui - por ser este o centro da minha pesquisa acadêmica - atravessa em especial a literatura portuguesa, que sobreviveu bravamente neste século XX a quase cinqüenta anos de ditadura salazarista, não estará de modo algum ausente a experiência pessoal de uma geração de brasileiros que se formou no silêncio das academias, entre as paredes brancas das universidades, no medo constrangido da repressão, na consciência da perda irreparável dos que desapareceram, dos que foram exilados, mortos ou mutilados por violências similares. Falarei assim de três tempos, a partir de três referências paradigmáticas: a da escrita sob censura, através de um dos romances mais bem conseguidos de José Cardoso Pires - $O$ Delfim; a da euforia revolucionária do Levantado do chão de José Saramago; e a do balanço dolorosamente esforçado do colonialismo e do pós-colonialismo, a partir de um texto que institui como valor a multiplicidade do olhar: Partes de Africa de Helder Macedo.

Escrever sob censura é escrever dilacerado, constrangimento que gera um percurso clandestino, uma necessária busca de estratégias onde o não-dito deve superar a força do evidente e do revelado. Jogo de metáforas, clandestinização do narrado. Quem não se lembra da MPB nos anos 60 e 70 quando uma doce sabiá, que o poeta acreditava que ainda "haveria de ouvir cantar", era o objeto lírico do desejo dessa outra "canção do exílio", que evocava a clássica urgência pessoal, nacionalista e romântica do grande poeta Gonçalves Dias, para, na verdade, saltar sobre ela e funcionar como metonímia do canto da revolução na pátria de todos os artistas brasileiros exilados pela Ditadura? Talvez seja bom relembrar os versos:

Vou voltar

Sei que ainda vou voltar 
Vou deitar á sombra de uma palmeira

Que já não há

Colher a flor

Que já não dá

E algum amor talvez possa espantar

As noites que eu não queria

$\mathrm{E}$ anunciar o dia

Vou voltar

Sei que ainda vou voltar

Não vai ser em vão

Que fiz tantos planos de me enganar

Como fiz enganos de me encontrar

Como fiz estradas de me perder

Fiz de tudo e nada de te esquecer

Vou voltar

É ainda lá

Que eu hei de ouvir cantar uma sabiá

Texto romântico e canção popular se respondem, mas não em uníssono, não no mesmo diapasão nem na mesma sintonia. O eu lírico romântico evocava do exílio a terra da bonança e da fartura, a terra do excesso, de todas as palmeiras, de todas as aves, de todas as estrelas, de todas as flores, de todos os rios e de todos os amores. Eldorado perdido, Pasárgada apenas vislumbrada pela memória, era lá que ele desejaria viver, era só lá que ele poderia imaginar a plenitude ou a utopia realizada.

Ora, não será este o espaço que ambiciona o exilado dos anos 70 no Brasil, porque a terra para onde o desejo o conduz é em tudo uma terra de carência, onde a noite escondeu o dia, terra de menos palmeiras, de menos pássaros, de menos flores e de menos vida . Estranho hedonismo que o faz ansiar pela "sombra de uma palmeira que já não há", ou que o faz desejar "colher a flor que já não dá”. Estranho hedonismo que o faz manter vivos os planos, mesmo que eles resultem em enganos de possíveis e desejados encontros, porque as estradas são caminhos de errância, de desagregação e de perdição.

Que força é essa, que evita o esquecimento do que parece perdido e incita o viajante a retornar do exílio? Aqui não há mais um Deus a ser invocado ("Não permita Deus que eu morra / sem que eu volte para lá, / sem qu'inda aviste as palmeiras / onde canta o sabiá’). Agora há tão somente uma decisão pessoal, reiterada e utopi- 
camente segura - "Vou voltar / Sei que ainda vou voltar" -, que nasce, não mais do desejo de reencontrar a utopia da plenitude realizada, mas, já agora, do impulso de realizar a utopia transformadora do real. A arma é simplesmente o amor, que espanta a noite e anuncia o dia, amor que faz nascer, do silêncio, da noite e da morte, o canto da sabiá, variante em vertente feminina de um sabiá passado, e que agora, tal qual a revolução, também feminina, é o único canto possível do amanhã. Ansiar pela terra da carência não é, pois, um paradoxo; é a crença na praxis geradora do mundo novo.

Quem não se lembra, ainda, que ouvíamos, com Apesar de você, do mesmo Chico Buarque, um suposto lamento romântico de amante sofrido a jurar "cobrar com juros" o seu sofrimento e vingar-se da dor quando o "amanhã" fosse "outro dia", com um galo a "insistir em cantar ", "água nova rolando e a gente se amando sem parar". Tudo isso, é claro, quando "chegasse o momento". Só que sabíamos todos que aquele "você" tinha endereço certo, que a cobrança excedia o meramente pessoal e o amor com que se sonhava era o de um tempo em que não houvesse mais "todo esse amor reprimido, esse grito contido esse samba no escuro".

Escrita no escuro é também uma das imagens possíveis para falar d'O Delfim, romance de José Cardoso Pires publicado em 1968, escrita que se funda sobre a estratégia de clandestinização do narrador ${ }^{4}$, que oculta da cena principal o evento fundador a que assiste o personagem-narrador - a posse da Lagoa pelo povo da Gafeira. Encobrindo a dinâmica social - espécie de preparação ou de mise-en abyme do que viria a operar-se em Portugal em 1975, no verão quente em que se efetiva a revolução agrária e a vitória sobre o Latifúndio - outros fatos são narrados, outras cenas descritas, outras vinganças executadas, numa espécie de relato policial que não nos engana porque está ele próprio comprometido enquanto gênero, já que ao final não se desvela o crime, não se conhecem os culpados e a punição não se pode cumprir. O que entretanto acontece efetivamente é a reversão definitiva de um sistema de privilégios, é a democratização no domínio da terra, é a vitória do povo sobre a dominação centenária das famílias de latifundiários poderosos. Em outras palavras o Delfim, tal como era conhecido o último representante dos Palma-Bravo, e que dicionarizado significa berdeiro do trono, bispo do jogo de xadrez, golfinho devorador de peixes menores, transforma-se em golfinho devorado pela lagoa, bispo em xeque, herdeiro sem poder. Em tempos de censura a revolução tinha que acontecer em pano de fundo, a euforia devia ser velada e assistida pelo Narrador da janela embaciada de seu posto de observador privilegiado na pensão da aldeia. Sobravam felizmente as metáforas: uma lagartixa imóvel sobre o muro descomunal de uma praça vazia e batida pelo sol de onde se ausentaram 
os homens - emigrantes para outras terras -, lagartixa ela própria identificada pelo escritor ao Tempo, que surpreendentemente se move e sai do sono de prisão para reapossar-se da História.

Posse da História foi, sem dúvida alguma, em Portugal, o 25 de abril de 1974. De longe, Chico Buarque a saúda, em dicção e tonalidade bem portuguesas - "Foi bonita a festa, pá" - seguidas entretanto do lamento que a Ditadura Militar brasileira fazia nascer: "Sei que há léguas a nos separar / Tanto mar, tanto mar". 25 de abril, viragem sem volta. Como bem disse Maria Alzira Seixo, ensaísta portuguesa, na comemoração do segundo ano da jovem Revolução:

Abril deixou de ser abril para tomar-se ponto de passagem, ou, melhor, ponto da passagem. [...] Assim, ao dizer 25 de Abril, eu digo igualmente: revolução. [Mas] se digo 25 de Abril e me encanto, paro, contemplativa. Para avançar, terei de dizer: 25 de Abril (o próximo, o outro). Então eu estabeleci um prolongamento, formei uma relação de contigüidade - de Abril a Abril, e já não é só a revolução que foi, é a revolução que é, e que será. ${ }^{5}$

Pois é nesse contexto de festa que se inscreve a segunda referência literária dessa seleção de textos da revolução: Levantado do chão, de José Saramago. Com este romance escreve-se a história da revolução agrária dos camponeses alentejanos, do seu difícil processo de amadurecimento ideológico ao longo de um doloroso século $\mathrm{XX}$, em que tiveram contra si uma estranha "LEI", tríade irônicamente dramática porque composta pelo poder do Latifúndio, do Estado e da Igreja, três potências que a revolução agrária de 1975 conseguiu abalar radicalmente por lhes roubar a força, o poder e a voz ${ }^{7}$. Compõe-se, assim, uma espécie de épica campesina, uma história de homens "levantados" de um chão, que é o solo alentejano (e, por extensão, português), história não mais de "barões assinalados", mas de camponeses sem nenhum sinal, que fazem a travessia do "mar interior" do "latifúndio"; história cuja proposição é "cantar" a "gente miúda que veio com a terra", para fazer a "escritura" dos que não têm história; que situa a terra do desejo em aldeias da revolução agrária - "Mantas e Pedra Grande, Vale da Canseira, Monte da Areia, Fonte Pouca, Muita Fome, Serralha, não há quem valha, por sobre colina e vale” (LC, p. 365). Fogem os Bertos, os poderosos da terra, deixando desocupado o Latifúndio, depois que o Estado autoritário ruiu com a Revolução de Abril; cala-se o Padre Agamedes, representante de uma Igreja falida, que não sabe o que dizer, e só "fala por parábolas", porque "a prudência da 
igreja é infinda"(LC, 354); também a "guarda não sai do posto" (LC, 364), porque o Cabo Tacabo, o Sargento Armamento ou o Tenente Contente - redundantes no próprio nome que os assinala sem os identificar - têm as "mãos atadas", faltam-lhes as ordens antigas para se voltarem contra os camponeses que invadem as terras abandonadas. Por isso, ao final do livro, "no mar interior do latifúndio, não pára a circulação das ondas" (LC, 363), "o sol é de justiça" (LC, 364) e os homens todos, os vivos e os mortos, vivem o apocalipse de uma revolução num "dia levantado e principal" (LC, 366). Não há melhores ingredientes para um discurso épico que se dá inclusive o direito de parar no tempo da glória conquistada. Possivelmente em 1980, data da publicação de Levantado do chão, já não seria assim tão plena a vitória dos camponeses alentejanos que em Portugal construíram as primeiras cooperativas agrícolas em regime comunitário. Mas, apesar de esta vitória histórica estar ameaçada pelas incontornáveis crises por que passa toda experiência inaugural, José Saramago se permite fazer da sua ficção um espaço de celebração da utopia realizada.

Estamos hoje a mais de 25 anos do 25 de Abril de 1974. Teria chegado ao fim a euforia revolucionária? De certo modo o ingrediente eufórico ganhou contornos mais realistas e o Portugal de hoje faz o balanço das propostas passadas e dos ganhos do presente. Os anos 90 trouxeram certamente um olhar mais sereno sobre as cantadas conquistas revolucionárias. O fato não ultrapassável é, no entanto, a própria revolução, e possivelmente uma das sínteses mais bem feitas desse processo está registrada no último romance de Helder Macedo, Pedro e Paula, num capítulo bem machadiano, em princípio dedicado ao registro do 25 de Abril, mas formado todo de reticências que ampliam os sentidos do dado referencial para neles incluir perdas e ganhos, plausibilidades e esperanças, e até aquela face enigmática em que os acertos podem gerar erros e os erros reverter-se em soluções, para ao final concluir de forma emblemática: "Mas festa é festa, e esta já ninguém nos tira"8.

Os anos 90, repito, são o tempo do balanço. E Partes de África, do mesmo Helder Macedo, são um paradigma desta forma polêmica de olhar a História. Romance feito de "partes", o título já o indica, em que o discurso é tecido com os fios da memória pessoal e da memória nacional. Revisita-se, assim, a história do eu como metonímia do processo nacional. "Quem pretende se aproximar do próprio passado soterrado diz Walter Benjamin - deve agir como um homem que escava", e o narrador de Partes de Africa se dispõe justamente a escavar e recordar a sua própria vida, assim como os últimos 50 anos de colonialismo português, espalhando os fatos como camadas de terra que entregam de forma generosa a "recompensa da escavação"10. O romance, 
que não abdica de um exercício de biografia e memorialismo - apesar de implodir conscientemente esses gêneros em suas acepções tradicionais de testemunhos incontestáveis da verdade histórica, porque desconfia inteligentemente da possibilidade de sua inteireza quando transformada em linguagem -, o romance, repito, começa e termina com a referência fundadora à morte do pai, ele próprio, enquanto homem do sistema, metonímia do jogo de poder em que o filho acreditara ocupar com certeza inabalável o virtuoso papel de revolucionário. Ora, o que o narrador descobre com a própria escrita é que, sepultado o pai, sepultava-se um tempo ao qual não se retornaria como modelo, mas ao qual era preciso retornar como reavaliador. E da luta maniqueísta dos contrários - oprimido / opressor, colonizado / colonizador, revolução / salazarismo, enfim, bem / mal - chega-se, não à anulação dos valores, mas à ponderação frutuosa da inserção de um terceiro termo que multiplica a direção dos olhares sobre o real, que instaura uma ética não autoritária, em que o novo não chega simplesmente para fazer tabula rasa do passado e substituir uma verdade por outra. Não há afirmação mais polêmica, para os que preferem a facilitação e a simplicidade dos opostos, que este balanço que afirma a excelência da democracia quando ela é capaz de ultrapassar os limites atrofiantes do quiasmo, "que só finge mudança para manter tudo na mesma"11 , e restaurar a fertilidade e a dinâmica do oximoron que é "quando o deserto é fértil, a secura molhada, o sol negro, a claridade escura. O oximoron [...] traz consigo a possibilidade da mudança, há sempre alguma esperança no oximoron”"12.

Essa interessante questão que levanta o oximoron - a da convivência construtora dos contrários, como via de evitar o binarismo redutor do bem contra o mal, do certo contra o errado - é que me fez escolher esse romance de Helder Macedo para ilustrar uma forma nova de escrever em liberdade, aquela que nem sequer necessita da divina fúria dos tempos revolucionários que puseram abaixo as cadeias da opressão política, para poder inaugurar um momento em que há que se repensar, para além dos antagonismos redutores, a revisão de ganhos e perdas que o passado legou ao presente. E isto me ocorreu porque também este romance nos permite refletir sobre uma questão muito atual nos debates brasileiros sobre liberdade, independência, castração, alteridade, colonialismo e pós-colonialismo, conceitos que parecem mais aguçados agora que celebramos os 500 anos da chegada dos portugueses ao Brasil. Há datas que não se podem esquecer, há questões que essas datas geram de que é fundamental falar. E eu quero falar delas a partir de um certo olhar desconstrutor que encontro em Partes de Affrica de que leio o seguinte trecho: 
"Reconhecer o desconhecido" - pressupõe um paradoxo: pois como reconhecer o que se desconhece? Mas esse, julgo eu, foi um paradoxo freqüentemente manifestado nos primeiros encontros entre povos de civilizações diferentes, a razão dos ilusórios entendimentos e dos equivocados desentendimentos que estiveram na origem da construção dos impérios. De modo que para falar dos Descobrimentos[...] vou procurar ilustrar [...] a maneira como os pioneiros da aventura imperial européia reconheceram o que não conheciam, projetando nas coisas e nos povos que foram encontrando os seus próprios desejos, medos, ideais, fantasmas, superstições - em suma, o seu imaginário. A palavra latina "invenire", que significa "encontrar" ou "descobrir", é também a raiz da palavra "inventar".

$[\ldots]$

De mal-entendidos são os impérios feitos. Quando os mal-entendidos começaram a esclarecer-se, quando o desconhecido deixa finalmente de ser reconhecido por aquilo que não é, e a norma da diferença se integra na norma que diferencia, então é porque já chegou o tempo do fim dos impérios, quando o pós-imperialismo se pode tornar na conseqüência positiva de ter havido impérios. E a verdade é que esse fim já estava contido no princípio. João de Barros, o cronista da fundação do império português, já o previa quando, em 1539, escreveu como justificação da sua Gramática que as armas e os padrões que Portugal disseminou por todos os continentes eram coisas materiais, que o tempo poderia destruir, mas que a língua portuguesa não seria tão facilmente destruída pelo tempo. É certo que, para tal acontecer, outras línguas se foram perdendo no caminho. Mas, pelo menos, agora, o poeta moçambicano José Craveirinha já pôde publicamente reivindicar Camões como parte da sua literatura; no Brasil é mesmo a língua portuguesa que se fala, por muito que doa a quem ache que deve doer; e os portugueses já começaram a descobrir que a sua língua não é apenas aquela que julgam reconhecer.

A longa citação que fui roubar a Partes de África, romance de Helder Macedo publicado em 1991, nos permitirá concluir coisas importantes sobre a relação entre povos, forma de pensarmos hoje, em tempos de 500 anos, as relações entre Portugal, Brasil e África.

1 - que, entre as muitas violências que a dominação dos povos fez nascer, não terá sido a menor delas a incapacidade de o outro conquistado ter sido conhecido na sua diferença, mas antes reconhecido através de um olhar já comprometido, cujo saber era anterior ao próprio ato do conhecimento e, por isso mesmo, autoritariamente poderoso e cego, gerando "ilusórios entendimentos" e "equivocados desentendimentos" (PA, p. 160); 
2 - que o passado inscrito é sem remédio e sem retorno, mas que o movimento da história se torna possível, apesar desse aparente fatalismo, pelo poder de amadurecimento das tensões que conduzem, a seu tempo, às crises, às revoluções e à ruína dos impérios;

3 - que, mais que isso, a experiência passada, neste caso o embate colonizador/colonizado, é também uma outra forma de saber, tantas vezes dolorosa, que funda, nesse movimento de continuidade ou de contestação, a história do presente e as propostas do futuro, na medida em que consegue ultrapassar, sem apagar, as contradições de que é feita. Só assim podemos entender a coragem de certas propostas do autor deste ousado romance que é Partes de África, que apostam no jogo criativo e dialético da história ao afirmarem que "o pós-imperialismo se pode tornar na conseqüência positiva de ter havido impérios" ou ainda que, apesar de outras línguas se terem ido perdendo no caminho - fato incontestável mas já agora também incontornável -, "o poeta moçambicano José Craveirinha já pôde publicamente reivindicar Camões como parte de sua literatura", e isto não é de modo algum desprezível.

Quis partir deste romance de Helder Macedo porque achei que a citação vinha bem a calhar para nós que vivemos há mais de 150 anos a experiência pós-imperial, ao menos em relação a Portugal. E também porque estamos a um mês apenas da passada comemoração oficial dos 500 anos da chegada dos portugueses ao Brasil, a um mês apenas de manifestações contraditórias, de uma pompa oficial que não chegou a contaminar o povo, e também de bombas e polícia, de índios e sem-terra, comemorações cuja metáfora mais concreta é a de uma nau encalhada que não consegue seguir rumo ao oceano.

Que é que na verdade não funcionou? Que é que se cobrou com um travo amargo na boca das comemorações desse fato histórico que foi indiscutivelmente fundamental e fundador dos brasileiros que hoje somos? Não haverá certamente uma só resposta a esta pergunta, mas alguma coisa pareceu bastante clara: os que muito justamente protestavam dirigiam-se menos às vicissitudes do passado e mais à sua absurda permanência no presente. Porque de enganos, de violências e de perdas, ou em outras palavras para falar com Helder Macedo, "de mal-entendidos são os impérios feitos", mas não será lançando as culpas no passado que faremos do Brasil um país à altura de si próprio, mais que isso - o que geralmente se oculta - à altura dos homens que aqui vivem.

O que esse romance de Helder Macedo pode assinalar, para além do seu cunho deslizantemente autobiográfico, para além da releitura da história dos últimos 50 anos 
do colonialismo português, é um viés muito novo de se constituir possivelmente como o primeiro romance verdadeiramente pós-colonial da literatura portuguesa, e com isto não estaríamos longe de concluir sobre a dificuldade que tal empresa propõe. Não se chega com facilidade ao fim de um império de 500 anos e quando digo isso não me refiro às opções políticas conscientes de grande parte da intelectualidade portuguesa. Refiro-me a uma mitologia do império que atravessara o imaginário do conquistador. Referir-se criticamente à violência da guerra colonial, ao destino trágico da colonização é um ato político louvável mas, de certo modo, plausível no universo de uma geração que lutou pela sua extinção mesmo que arbitrariamente vivendo a luta do lado do poder. Analisar vinte anos depois - e em termos de História isso não é muito - o destino de ambos os lados em tempos verdadeiramente pós-coloniais é empresa mais difícil e tem que lidar menos com antagonismos do que com deslizamentos da verdade, menos com oposições do que com uma espécie de terceiro termo ambivalente que descobre $o$ sim nos interstícios do não para se chegar, quem sabe, à saudável idéia de que diante da irreversibilidade dos tempos há que se pensar corajosamente no saldo positivo de ter havido impérios.

Nos encontros entre Portugal e Brasil não cessaríamos de apontar contradições, e é bom que continuemos a fazê-lo. Bom, entretanto, é poder também afirmar que ao longo de um imenso território nacional, ao longo desse nosso país de dimensões continentais, "é bem a língua portuguesa que se fala" e que esse é um legado indestrutível e uma herança que o Brasil pós-colonial não quis recusar. Bom é poder descobrir que, numa espécie de antropofagia salutar, a língua portuguesa ultrapassou o estatuto da doação e da herança do colonizador, que ela ganhou foro de propriedade, de tal modo que hoje - possivelmente sem se dar conta da ousadia da observação - para o brasileiro, é o português que fala com sotaque: saborosa afirmação de que a imposição se tornou opção. Bom é poder ter também Camões ou Eça de Queirós como parte de nossa literatura, não como monumentos, mas como fontes revisitadas para matar nossa sede de poesia. Bom, enfim, é saber que, em caminho de mão dupla, também Machado ou Guimarães ou Graciliano, e Drummond e Clarice e Cecília, e tantas outras vozes brasileiras assinalam com seu timbre tropical a produção da literatura portuguesa. Por isso, talvez, essa é mesmo a hora de afirmar que o "pós-imperialismo pode se tornar na conseqüência positiva de ter havido impérios". Sem nenhuma perspectiva - por longínqua que seja - de homogeneização, os saberes interagem, numa mesma e outra língua que é a língua portuguesa. Por isso, como dizíamos antes, não se trata de imaginar, em casos como esses, uma possível revanche do colonizado. 
Para além dessa visão estreita e pobremente redutora dos contatos culturais, está um espaço sem fronteiras que é o da literatura, da arte, da cultura enfim, em que os saberes generosamente dialogam como vasos comunicantes a fertilizarem um campo comum.

Esses momentos em que se busca ler inteligentemente a História são possibilidade de um tempo em que já não é preciso "murmurar entre as pregas”, e em que já se pôde - e eu me refiro aqui especificamente a Portugal - chegar a um estágio em que a luta por um mundo melhor, por uma eu-topia, se pode fazer, para além das batalhas, para além dos confrontos, na revolução constante do dia-a-dia. Quando mais que estabelecer as categorias de certo e errado ou bem e mal, acredita-se que ultrapassar a opressão é também saber compreender a fertilidade do deserto ou a negrura do sol, é porque começamos a vislumbrar uma saída, uma mudança, uma esperança que ultrapasse o evidentemente saudável apocalipse libertário para se instituir como verdadeira e fecunda experiência de liberdade. Do escritor exilado de si próprio e do espaço cívico a que tem direito chegamos ao escritor que fala dos ganhos e perdas do passado como constituintes do seu presente de liberdade. Que não é certamente o tempo do bem instituído ou do Eldorado conquistado, mas um tempo em que para além do sim constrangido dos tempos da opressão ou para além do não sonoramente gritado em nome da revolução, chega-se à possibilidade do talvez que só é possível quando a liberdade pôde ter algum lugar. Só em liberdade o artista pode sonhar em ultrapassar os próprios excessos da festa, não por renegá-la, mas porque ela se torna, ao contrário, fato verdadeiramente grande, introjetado, incontornável, que nos ensina a ser vigilantes não para cantar "a revolução que foi, mas a revolução que é e que será"13.

\section{$\operatorname{son}$}

\section{NOTAS}

1 E agora, José? p.28

2 E agora, José? p.29

3 E agora, José? p.97-98

4 LEPECKI, Maria Lúcia.

5 SEIXO, M.A. Discursos do texto. Lisboa, Bertrand, 1977. P.25-26

6 SILVEIRA, Jorge Fernandes da. “Os Pos-tugueses”. In: Folhetim - Folha de São Paulo, 6a feira, 22-04-1988, número 585. 
7 Diz: "porque de todos os lugares percorridos e ocupados [...] nem falando nem cantando, nem calando nem chorando, estão Norbertos e Gilbertos ausentes, para onde foram, sabe-se lá. A guarda não sai do posto, os anjos varrem o céu, é dia de revolução, quantos são." (LC, 364, grifos nossos)

8 MACEDO, Helder. Pedro e Paula. Rio de Janeiro, Ed. Record, 1999. p.117-118

9 BENJAMIN, Walter. Rua de mão única. São Paulo, Ed. Brasiliense, 1987. P.239

10 Idem, ibidem.

11 MACEDO, Helder. Partes de África. Lisboa, Presença, 1991. P.150

12 Idem, ibidem

13 SEIXO, M.A. op.cit. à saudável experiência de escrever em liberdade. Légua \& meia: revista de literatura e diversidade cultural. Feira de Santana:

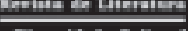

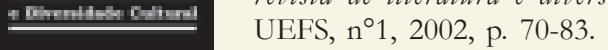

Teresa Cristina Cerdeira da Silva é Professora Adjunta da UFRJ. Licenciada em Letras pela UFRJ, Mestre na Universidade de Toulouse-le Mirail e na UFRJ, Doutora em Literatura Portuguesa pela UFRJ, Pós-Doutorado na Universidade de Lisboa. Seus ensaios mais importantes estão publicados em dois livros: José Saramago: Entre a bistória e a ficção, uma saga de portugueses, 1997, e O Avesso do bordado, 2000. 